\title{
Палеоархейские ТТГ и метапелиты - протолиты неоархейских риолитов А-типа Курского блока Сарматии: результаты экспериментов по дегидратационному плавлению
}

\author{
(C) 2021 К. А. Савко ${ }^{1,2 \unrhd}$, А. В. Самсонов ${ }^{3}$, М. А. Голунова ${ }^{4}$, \\ К.-Л. Вонг ${ }^{5}$, Н. С. Базиков ${ }^{1}$, Н. В. Холина ${ }^{1}$, Т. Н. Полякова ${ }^{1}$ \\ ${ }^{1}$ Воронежский государственивй университет, \\ Университетская пл., 1, 394018, Воронеж, Российская Федерация \\ ${ }^{2}$ Российский государственный геологоразведочный университет, Старооскольский филиал, ул. \\ Ленина, 14/13, 309530, Старый Оскол, Белгородская область, Российская Федерация \\ ${ }^{3}$ Ииститут геологии рудных месторождений, петрографии, минералогии и геохимии Россий- \\ ской академии наук, Старомонетный пер., 35, 119017, Москва, Российская Федерация \\ ${ }^{4}$ Институт экспериментальной минералогии Российской академии наук \\ им. Д. С. Коржинского, ул. Академика Осипьяна, 4, \\ 142432, Черноголовка, Московская область, Российская Федерация \\ ${ }^{5}$ Институт наук о Земле, Академия Синика, Тайбей, Тайвань
}

\begin{abstract}
Аннотация
Bведение: В Курском блоке Восточной Сарматии внутриплитный магматизм А-типа с возрастом 2.61 млрд лет представлен вулкано-плутонической ассоциацией калиевых высококремнистых риолитов и гранитов. Изотопные данные свидетельствуют о гетерогенности корового источника данных пород. По данным моделирования материнские расплавы могли образоваться при $20 \%$ дегидратационном плавлении смеси метапелит-ТТГ при давлении не более 4 кбар.

Методика: Для проверки выводов, основанных на численном моделировании геохимических данных, были выполнены опыты по экспериментальному плавлению вероятных протолитов. В полученных препаратах был проанализирован химический состав расплава и реститовых минеральных фаз.

Результаты и обсуждение: Состав экспериментального расплава, полученного при температуре $950^{\circ} \mathrm{C}$, по содержанию петрогенных оксидов близок к неоархейскому риолиту из Курского блока. Усредненные кривые распределения редкоземельных элементов в экспериментальном расплаве также близки к неоархейским риолитам.

Заключение: Экспериментальные исследования показали возможность образования неоархейских риолитовых магм А-типа при высоких температурах на неболыших глубинах в результате частичного плавления палеоархейской коры, состоящей из ТТГ и метаосадков в Курском блоке Сарматии. Ключевые слова: архей, риолиты, протолит, экспериментальное плавление

Источник финансирования: Работа поддержана проектом РФФИ № 19-05-00159.

Для циитирования: Савко К. А., Самсонов А. В., Голунова М. А., Вонг К.-Л., Базиков Н. С., Холина Н. В., Полякова Т. Н. Палеоархейские ТТГ и метапелиты - протолиты неоархейских риолитов Атипа Курского блока Сарматии: результаты экспериментов по дегидратационному плавлению // Вестник Воронежского государственного университета. Серия: Геология. 2021. №2. С. 29-40. DOI: https://doi.org/10.17308/geology.2021.2/3486
\end{abstract}

Контент доступен под лицензией Creative Commons Attribution 4.0 License.

Савко Константин Аркадьевич, e-mail: ksavko@geol.vsu.ru 


\section{Введение}

В пределах Курского блока Восточной Сарматии локально проявлен внутриплитный гранитоидный магматизм А-типа с возрастом 2.61 млрд лет, представленный вулкано-плутонической ассоциацией калиевых высококремнистых риолитов и гранитов [1]. По данным минеральной геотермобарометрии (TiQ и TiZr) и геохимии циркона из риолитов в магматическом очаге, находившемся на глубине не более 7 км, температуры плавления составляли $900-1000^{\circ} \mathrm{C}$ [2].

Железистые калиевые граниты А-типа могут образоваться при частичном плавлении различных типов пород - от средних до основных, содержащих биотит и амфибол, метаграувакк и метапелитов при высоких температурах $\left(>900^{\circ} \mathrm{C}\right)[3$ и ссылки в ней].

Тремя основными способами их формирования являются [4]: (1) частичное плавление кварц-полевошпатовых коровых пород, (2) дифференциация базальтовых магм, (3) комбинация первых двух с дифференциацией базальтовой магмы и ассимиляцией корового вещества (АFC - процесс).

$\mathrm{Lu}-\mathrm{Hf}$ изотопные исследования циркона и $\mathrm{Sm}-\mathrm{Nd}$ валовых проб свидетельствуют о гетерогенности корового источника для неоархейских внутриплитных риолитов и гранитов Курского блока, основными компонентами которого, вероятно, были архейские метапелиты и гранитоиды ТТГ ассоциации $[1,5]$. По данным моделирования содержаний РЗЭ материнские расплавы для внутриплитных риолитов и гранитов с возрастом 2.61 млрд лет могли образоваться при 20\% дегидратационном плавлении смеси метапелит-ТТГ при давлении не более 4 кбар [1].

Для проверки этих выводов об источниках расплавов, температурах и степени частичного плавления неоархейских калиевых риолитов А-типа в Курском блоке Сарматии, основанных на численном моделировании геохимических данных [1], были выполнены опыты по экспериментальному «сухому» плавлению наиболее вероятных протолитов (палеоархейские ТТГ + метапелиты). Стартовыми материалами для плавления являются образцы архейских ТТГ и метапелитов из скважин в пределах Курского блока Сарматии. В полученных экспериментальных препаратах было проанализировано распределение петрогенных оксидов, редких и редкоземельных элементов в расплаве и реститовых минеральных фазах.

Ранее в экспериментах по частичному плавлению коровых пород с целью получения гранитоидных расплавов А-типа проводился анализ только петрогенных оксидов $[3,6,7,8]$ из-за сложности учета влияния акцессорных фаз на распределение редких и редкоземельных элементов в системе расплав-рестит.

\section{Описание экспериментов}

Cтартовые материаль. Плавлению подверглась смесь трондьемита (скв. 3759, глуб. 461.7 м) и метапелита (скв. 3554, глуб. 224.5). Для выбора условий эксперимента мы ориентировались на полученные нами данные для неоархейских риолитов А-типа Курского блока (900-1000 ${ }^{\circ} \mathrm{C}, 4$ кбар, относительно сухие условия плавления) [1] и эксперименты по сухому плавлению ТТГ и биотитовых гнейсов при низких давлениях $[6,7,8]$. Составы проб трондьемита и метапелита приведены в таблице 1 .

Условия проведения экспериментов. Эксперименты проведены в Институте экспериментальной минералогии РАН на установке высокого газового давления УВГД-10000 с внутренним нагревом («газовая бомба»). Она позволяет достигать давления до 6 кбар и температуры до $1400^{\circ} \mathrm{C}$. Точность регулировки температуры составляет $\pm 5^{\circ} \mathrm{C}$, давления \pm 5 МПа. Регулировка и поддержание необходимой температуры в рабочей камере печи осуществляется с помощью терморегулятора TRM-101 OVEN через две термопары Sтипа (Pt90Rh10 - Pt100). Термопары установлены сверху и близко к нижней части камеры для управления температурным градиентом. Давление в системе устанавливается чистым давлением газа Ar. Крышка рабочей камеры изготовлена из пирофиллита. Оксид алюминия и каолиновая вата служат наполнителем в камере с ампулами. Эксперименты проводились в $\mathrm{Pt}$ ампулах при давлении 4 кбар и температурах $850^{\circ} \mathrm{C}$ и $950^{\circ} \mathrm{C}$ длительностью 7 суток. Закалка происходит при быстром снижении температуры до комнатной.

Для определения содержаний петрогенных оксидов в стекле (расплаве) и минеральных фазах экспериментальные образцы исследовались методом сканирующей электронной микроскопии высокого разрешения в Институте экспериментальной минералогии РАН на электронном сканирующем микроскопе Tescan Vega II $\mathrm{XMU}$ с энергодисперсионным спектрометром INCA Energy 450 (полупроводниковый $\mathrm{Si}(\mathrm{Li})$ детектор INCA x-sight) и волновым дисперсионным спектрометром INCA Wave 700 при ускоряющем напряжении 20 кB, a также на цифровом сканирующем электронном микроскопе (СЭМ) CamScan MV 2300.

Содержания редких и рассеянных элементов в стекле (расплаве) и минералах определялись методом лазерной абляции с индуктивно связанной плазмой (масс-спектрометрия LA-ICP-MS) в Институте наук о Земле Академии Синика (г. Тайбэй, Тайвань) с помощью лазерной системы Excimer 193 nm (Teledyne CETAC Analyte G2) вместе с квадрупольным масс-спектрометром Agilent 7900. Подробная процедура анализа описана в работе [9]. Время абляции составляло 70 с при частоте лазерного излучения 4 Гц с диаметром пятна 30-40 мкм и плотностью потока энергии 6.7 Дж/см². Для калибровки использовался стандарт NIST SRM 612 [10], а стандарт стекла USGS BCR-2G был проанализирован в качестве эталонного материала. Каждые двенадцать анализов стекла и минералов препарата сопровождались двумя анализами стандартных образцов. Обработка данных проводилась с использованием версии 4.4 программного обеспечения GLITTER (c) «в реальном времени» [11] сразу после каждого анализа. Минимальный предел обнаружения (MDL) с уровнем достоверности 99\% составлял около 0.1 ppm для $\mathrm{Rb}, \mathrm{Sr}, \mathrm{Zr}, \mathrm{Nb}, \mathrm{Ba}$ и около 0.01 ppm для РЗЭ. 
Повторные измерения на стандарте USGS BCR-2G дали $1 \sigma<3 \%$ и точность $<6 \%$ для определяемых элементов.

\section{Результаты экспериментов}

Onыm $850^{\circ} \mathrm{C} u 4$ кбар. В опыте при $850^{\circ} \mathrm{C}$ мы получили относительно равномернозернистую породу с гранобластовой структурой без отчетливо видимых признаков плавления (рис. 1a). Она содержит минеральную ассоциацию $\mathrm{Qtz}+\mathrm{Pl}+\mathrm{Kfs}+\mathrm{Bt}+\mathrm{Crd}+\mathrm{Sil}$, характерную для палеоархейских метапелитовых гранулитов Курского блока $[13,14]$. Точки микрозондовых анализов минеральных фаз показаны на рис. 1, составы минералов приведены в таблице 2.

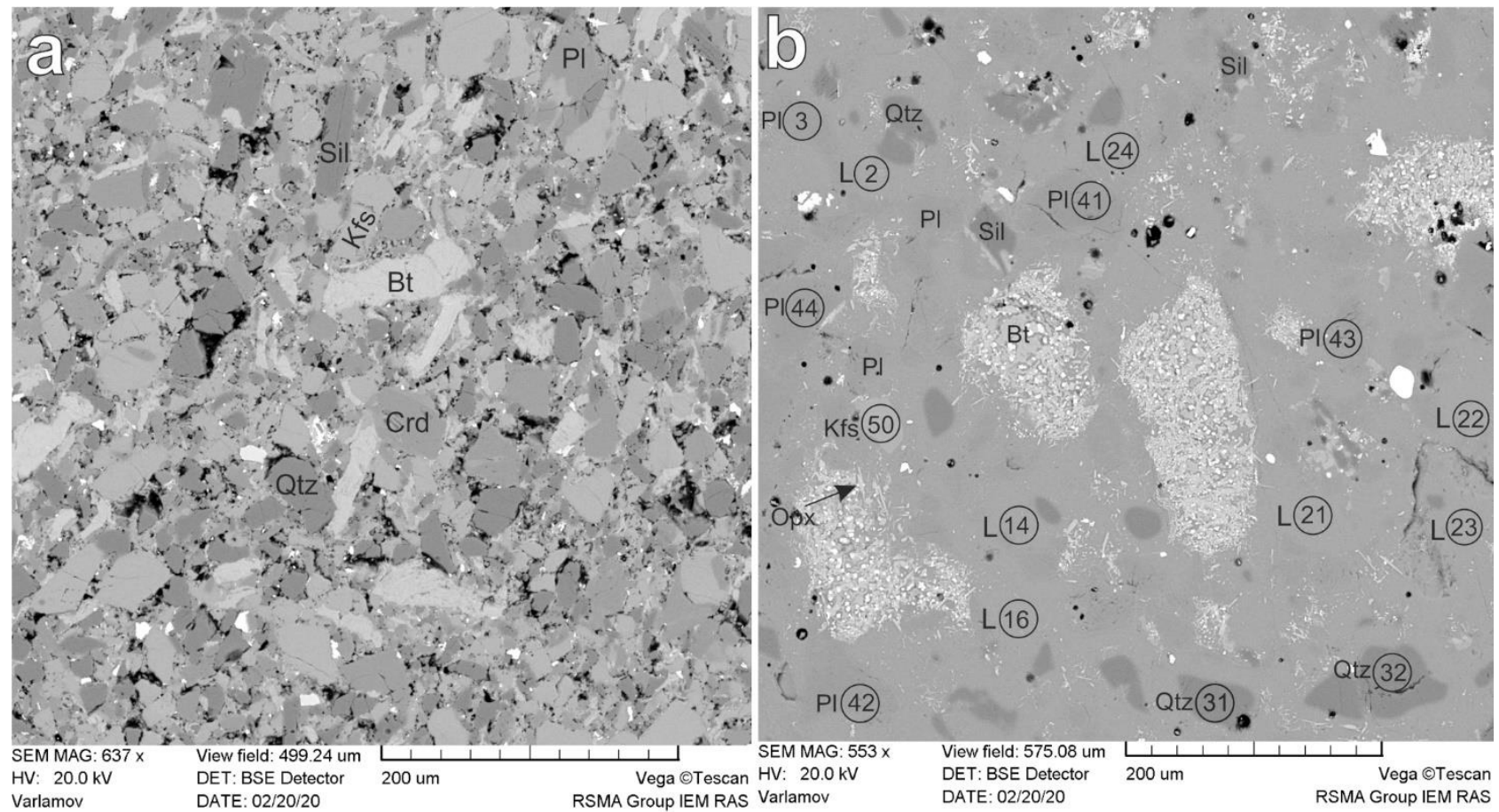

Рис. 1. Снимки экспериментальных образцов в отраженных электронах: $a$ - эксперимент при $850^{\circ} \mathrm{C}$ и 4 кбар; $b$ - эксперимент при $950^{\circ} \mathrm{C}$ и 4 кбар. Символы минералов по [12]. L - расплав. Кружками показаны места анализов минералов и расплава методом LA-ICP-MS, диаметр кружков соответствует области возбуждения лазерной абляции.

[Fig. 1. BSE-images of the experimental samples: $(a)$ - experiment at $850{ }^{\circ} \mathrm{C}$ and $4 \mathrm{kbar} ;(b)$ - experiment at $950{ }^{\circ} \mathrm{C}$ and $4 \mathrm{kbar}$. Mineral abbreviations are after [12]. L - melt. The sites of LA-ICP-MS analysis are shown by circles.]

В опыте при $950^{\circ} \mathrm{C}$ и 4 кбар полученный экспериментальный образец содержит около $20 \%$ стекла (расплава). В рестите преобладают кварц, плагиоклаз, калиевый полевой шпат, биотит (рис. 1b). В значительно меньшем количестве присутствуют силлиманит и ортопироксен. Экспериментальный расплав имеет содержания $\mathrm{SiO}_{2}$ от 70.9 до 73.5 мас. \% (среднее 72.5 мас. \%), перглиноземистый состав (А/CNK от 1.1 до 1.3), повышенное содержание щелочей $\left(\mathrm{K}_{2} \mathrm{O}+\mathrm{Na}_{2} \mathrm{O}=8.0-8.9\right.$ мас. \%) с преобладанием калия над натрием $\left(\mathrm{K}_{2} \mathrm{O} / \mathrm{Na}_{2} \mathrm{O}\right.$ от 2.1 до 2.6) (табл. 1, рис. 2). Он обогащен $\mathrm{TiO}_{2}(0.15-$ 0.55 мас. $\%$, ср. 0.41 мас. \%), характеризуется умеренной железистостью $\left(\mathrm{X}_{\mathrm{Fe}}=0.47-0.58\right)$ за исключением одной точки анализа $(0.38)$ и имеет невысокие отношения $\mathrm{Fe}_{2} \mathrm{O}_{3} / \mathrm{TiO}_{2}$ от 2.4 до 10.8. Таким образом, по содержанию петрогенных оксидов экспериментальный расплав близок к составу неоархейских риолитов Курского блока (рис. 3).

По геохимическим характеристикам расплав характеризуется низкими концентрациями $\mathrm{Sr}$ (32-104, cp. 70 ppm), Cr (1-42, cp. 11 ppm), высокозарядных $\operatorname{Zr}$ (3.2-35 ppm, cp.13.4 ppm), Nb (3.5-19.8, cp. 10 ppm), Ta (0.1-
0.9 ppm, ср. 0.44 ppm), Y (2.3-17.3, ср. 8.7 ppm), Тh (0.9-18 ppm, ср. 8.3 ppm) и редкоземельных элементов ( $\left.\sum \mathrm{REE}=22-165 \mathrm{ppm}\right)$ (табл. 1). Умеренные содержания имеют $\mathrm{Rb}$ (54-260, ср. 136 ppm) и Ва (до 1935 ppm). Редкоземельные элементы (REE) также характеризуются сильно обогащенными спектрами LREE ( $\mathrm{La}_{\mathrm{N}} / \mathrm{Yb}_{\mathrm{N}}$ = 15-70), умеренно фракционированными HREE $\left(\mathrm{Gd}_{\mathrm{N}} / \mathrm{Yb}_{\mathrm{N}}=2.0-5.4\right)$ и резкими положительными $\mathrm{Eu}$ аномалиями $\left(\mathrm{Eu} / \mathrm{Eu}^{*}=1.3-2.1\right)$ (табл. 1, рис. 4).

Кроме того, нами были определены содержания редких и редкоземельных элементов в реститовых плагиоклазе $\left(\mathrm{An}_{31-36}\right)$, калиевом полевом шпате и кварце. Остальные минералы (биотит, силлиманит и ортопироксен) не проанализированы из-за их очень небольшого размера - меньше области возбуждения лазерной абляцией (30-40 мкм). Полевые шпаты имеют близкий характер распределения редких и редкоземельных элементов и формы кривых на спайдер-диаграммах (рис. 5), хотя и обнаруживают разные содержания редкоземельных элементов. Все они характеризуются обогащением LREE $\left(\mathrm{La}_{\mathrm{N}} / \mathrm{Yb}_{\mathrm{N}}=\right.$ 15-103), умеренно фракционированными HREE 
$\left(\mathrm{Gd}_{\mathrm{N}} / \mathrm{Yb}_{\mathrm{N}}=1.0-5.8\right)$ и резкими положительными аномалиями $\mathrm{Eu}\left(\mathrm{Eu} / \mathrm{Eu}^{*}=2.0-6.9\right)$ (табл. 2). В целом характер распределения РЗЭ в экспериментальном расплаве и полевых шпатах сходен, только послед- ние имеют более резкие положительные Еu аномалии. В кварце установлены повышенные концентрации Тi, что свидетельствует о его высокотемпературной кристаллизации.

Табл. 1. Содержания петрогенных оксидов и редких элементов в экспериментальном расплаве и стартовых материалах [Table 1. Major oxides and trace elements concentrations in experimental melt and initial materials]

\begin{tabular}{|c|c|c|c|c|c|c|c|c|c|c|}
\hline & \multicolumn{8}{|c|}{$\begin{array}{c}950^{\circ} \mathrm{C} \text { и } 4 \text { кбар } \\
{\left[950^{\circ} \mathrm{C} \text { and } 4 \text { kbar }\right]}\end{array}$} & $\begin{array}{c}\text { Трондьемит } \\
\text { [Trodhjenmite] }\end{array}$ & $\begin{array}{l}\text { Метапелит } \\
\text { [Metapelite] }\end{array}$ \\
\hline & L-2 & L-14 & L-16 & L-21 & $\mathrm{L}-22$ & L-23 & $\mathrm{L}-24$ & $\begin{array}{c}\mathbf{L}_{\text {cp. }} \\
{\left[\mathbf{L}_{\text {avg }}\right]}\end{array}$ & $\begin{array}{c}3759 / \\
465\end{array}$ & $\begin{array}{l}3554 / \\
224.5\end{array}$ \\
\hline $\mathrm{SiO}_{2}$ & 72.08 & 70.91 & 72.96 & 73.51 & 73.24 & 71.66 & & 72.39 & 69.79 & 63.96 \\
\hline $\mathrm{TiO}_{2}$ & 0.55 & 0.53 & 0.15 & 0.42 & 0.40 & 0.51 & & 0.43 & 0.33 & 0.83 \\
\hline $\mathrm{Al}_{2} \mathrm{O}_{3}$ & 14.18 & 13.69 & 13.91 & 14.41 & 12.90 & 13.12 & & 13.70 & 14.65 & 16.89 \\
\hline $\mathrm{Fe}_{2} \mathrm{O}_{3 \text { tot }}$ & 1.31 & 1.51 & 1.62 & 1.50 & 1.68 & 2.30 & & 1.65 & 3.05 & 4.77 \\
\hline $\mathrm{MgO}$ & 0.58 & 0.86 & 0.60 & 0.68 & 1.40 & 1.64 & & 0.96 & 1.93 & 3.14 \\
\hline $\mathrm{MnO}$ & - & 0.05 & 0.21 & 0.17 & 0.17 & 0.11 & & 0.12 & 0.04 & 0.04 \\
\hline $\mathrm{CaO}$ & 0.39 & 0.77 & 0.83 & 0.74 & 0.54 & 0.49 & & 0.63 & 2.41 & 0.35 \\
\hline $\mathrm{Na}_{2} \mathrm{O}$ & 2.41 & 2.74 & 2.48 & 2.90 & 2.40 & 2.63 & & 2.59 & 4.16 & 0.96 \\
\hline $\mathrm{K}_{2} \mathrm{O}$ & 5.63 & 6.00 & 6.33 & 5.99 & 5.62 & 5.59 & & 5.86 & 2.22 & 7.45 \\
\hline $\mathrm{P}_{2} \mathrm{O}_{5}$ & - & - & - & - & - & - & & - & 0.10 & 0.04 \\
\hline $\begin{array}{l}\text { П.п.П. } \\
\text { [LOI] }\end{array}$ & - & - & - & - & - & - & & - & 1.05 & 0.54 \\
\hline $\begin{array}{l}\text { Сумма } \\
\text { [Total] }\end{array}$ & 97.14 & 97.05 & 99.08 & 100.32 & 98.36 & 98.06 & & 98.63 & 99.73 & 99.01 \\
\hline $\mathrm{Na}_{2} \mathrm{O}+\mathrm{K}_{2} \mathrm{O}$ & 8.04 & 8.74 & 8.81 & 8.89 & 8.02 & 8.22 & & 8.45 & 6.38 & 8.41 \\
\hline $\mathrm{K}_{2} \mathrm{O} / \mathrm{Na}_{2} \mathrm{O}$ & 2.34 & 2.19 & 2.55 & 2.07 & 2.34 & 2.13 & & 2.26 & 0.53 & 7.76 \\
\hline $\mathrm{X}_{\mathrm{Mg}}$ & 0.53 & 0.47 & 0.58 & 0.53 & 0.38 & 0.59 & & 0.54 & 0.56 & 0.57 \\
\hline $\mathrm{A} / \mathrm{CNK}$ & 1.31 & 1.10 & 1.12 & 1.14 & 1.17 & 1.16 & & 1.16 & 1.07 & 1.64 \\
\hline $\mathrm{Li}$ & 12.2 & 58.5 & 344 & 31.2 & 13.4 & 48.2 & 21.7 & 75.6 & 16.0 & 18.3 \\
\hline $\mathrm{Sc}$ & 2.7 & 35.0 & 132 & 5.99 & 2.66 & 12.5 & 5.79 & 28.1 & 3.0 & 25.0 \\
\hline $\mathrm{Cr}$ & 0.9 & 41.8 & 150 & 3.26 & 1.14 & 10.4 & 6.47 & 30.6 & 43.1 & 44.8 \\
\hline $\mathrm{Rb}$ & 54.4 & 260 & 1599 & 135 & 58.1 & 208 & 99.3 & 345 & 70.2 & 159 \\
\hline $\mathrm{Sr}$ & 64.9 & 82.6 & 1440 & 69.5 & 31.8 & 104 & 67.8 & 266 & 483 & 23.8 \\
\hline $\mathrm{Y}$ & 2.32 & 16.8 & 99.6 & 6.37 & 3.53 & 17.3 & 6.14 & 21.8 & 8.0 & 34.5 \\
\hline $\mathrm{Zr}$ & 3.17 & 16.4 & 216.3 & 8.1 & 7.03 & 34.5 & 11.0 & 42.4 & 195 & 948 \\
\hline $\mathrm{Nb}$ & 4.64 & 15.3 & 194 & 8.15 & 3.48 & 19.8 & 8.58 & 36.2 & 6.3 & 27.3 \\
\hline $\mathrm{Cs}$ & 0.84 & 3.97 & 24.7 & 2.42 & 1.04 & 3.16 & 1.39 & 5.4 & 1.5 & 1.5 \\
\hline $\mathrm{Ba}$ & 406 & 1935 & 22290 & 1249 & 479 & 1797 & 1009 & 4166 & 1103 & 3334 \\
\hline $\mathrm{La}$ & 5.5 & 40.8 & 288 & 24.3 & 22.4 & 40 & 18.0 & 62.7 & 32.4 & 93.2 \\
\hline $\mathrm{Ce}$ & 9.4 & 66.0 & 444 & 40.3 & 29.3 & 68.2 & 29.1 & 98.0 & 67.8 & 178 \\
\hline Pr & 1.04 & 6.7 & 43.8 & 3.92 & 2.69 & 7.37 & 3.04 & 9.8 & 6.9 & 6.5 \\
\hline $\mathrm{Nd}$ & 3.44 & 25.0 & 162 & 13.6 & 8.92 & 27.0 & 11.9 & 36.0 & 24.7 & 88.1 \\
\hline $\mathrm{Sm}$ & 0.69 & 4.75 & 35.4 & 2.77 & 1.62 & 5.94 & 2.57 & 7.7 & 4.0 & 18.5 \\
\hline $\mathrm{Eu}$ & 0.48 & 2.36 & 21.0 & 1.58 & 0.87 & 2.33 & 1.26 & 4.27 & 1.1 & 3.6 \\
\hline $\mathrm{Gd}$ & 0.70 & 4.34 & 30.2 & 2.12 & 1.51 & 5.07 & 2.31 & 6.61 & 3.1 & 16.8 \\
\hline $\mathrm{Tb}$ & 0.10 & 0.69 & 4.52 & 0.31 & 0.18 & 0.77 & 0.29 & 0.98 & 0.39 & 2.3 \\
\hline Dy & 0.59 & 4.05 & 24.1 & 1.79 & 0.91 & 4.02 & 1.68 & 5.31 & 1.7 & 11.3 \\
\hline Ho & 0.098 & 0.84 & 4.89 & 0.25 & 0.14 & 0.75 & 0.3 & 1.04 & 0.30 & 1.8 \\
\hline $\mathrm{Er}$ & 0.27 & 2.37 & 11.5 & 0.69 & 0.37 & 1.71 & 0.71 & 2.52 & 0.84 & 4.4 \\
\hline $\mathrm{Tm}$ & 0.032 & 0.28 & 1.53 & 0.075 & 0.046 & 0.20 & 0.079 & 0.32 & 0.11 & 0.54 \\
\hline $\mathrm{Yb}$ & 0.25 & 1.83 & 10.0 & 0.48 & 0.23 & 1.54 & 0.53 & 2.12 & 0.76 & 4.2 \\
\hline $\mathrm{Lu}$ & 0.03 & 0.29 & 1.48 & 0.64 & 0.032 & 0.20 & 0.076 & 0.39 & 0.11 & 0.68 \\
\hline $\mathrm{Hf}$ & 0.088 & 0.43 & 5.64 & 0.19 & 0.16 & 0.84 & 0.32 & 1.1 & 4.9 & 31.3 \\
\hline $\mathrm{Ta}$ & 0.21 & 0.60 & 7.0 & 0.25 & 0.13 & 0.92 & 0.52 & 1.38 & 0.48 & 1.1 \\
\hline $\mathrm{Pb}$ & 14.46 & 69.7 & 472 & 33.7 & 14.9 & 60.9 & 32.1 & 99.7 & 7.9 & 36.1 \\
\hline Th & 0.92 & 18.0 & 54.3 & 5.27 & 11.6 & 8.7 & 5.17 & 14.9 & 8.0 & 30.4 \\
\hline $\mathrm{U}$ & 0.16 & 1.71 & 13.3 & 0.52 & 0.29 & 2.3 & 0.94 & 2.75 & 1.8 & 5.62 \\
\hline$\sum$ REE & 22.6 & 160 & 1082 & 92.8 & 69.2 & 165 & 71.9 & 238 & 144 & 430 \\
\hline $\mathrm{Eu} / \mathrm{Eu}^{*}$ & 2.11 & 1.6 & 1.96 & 2.0 & 1.7 & 1.3 & 1.6 & 1.83 & 0.96 & 0.62 \\
\hline$(\mathrm{Gd} / \mathrm{Yb})_{\mathrm{N}}$ & 2.32 & 2.0 & 2.5 & 3.7 & 5.4 & 2.7 & 3.6 & 2.58 & 3.4 & 3.3 \\
\hline$(\mathrm{La} / \mathrm{Yb})_{\mathrm{N}}$ & 15.8 & 16.0 & 20.7 & 36.31 & 69.86 & 18.6 & 24.4 & 21.2 & 30.6 & 15.9 \\
\hline $\mathrm{Sr} / \mathrm{Y}$ & 28.0 & 4.9 & 14.5 & 10.9 & 9.0 & 6.01 & 11.0 & 12.2 & 60 & 0.69 \\
\hline
\end{tabular}

Примечание: $\mathrm{X}_{\mathrm{Mg}}-\operatorname{molar} \mathrm{Mg} /(\mathrm{Fe}+\mathrm{Mg}) ; \mathrm{A} / \mathrm{CNK}\left(\operatorname{molar} \mathrm{Al}_{2} \mathrm{O}_{3} /\left(\mathrm{CaO}+\mathrm{Na}_{2} \mathrm{O}+\mathrm{K}_{2} \mathrm{O}\right)\right.$. 


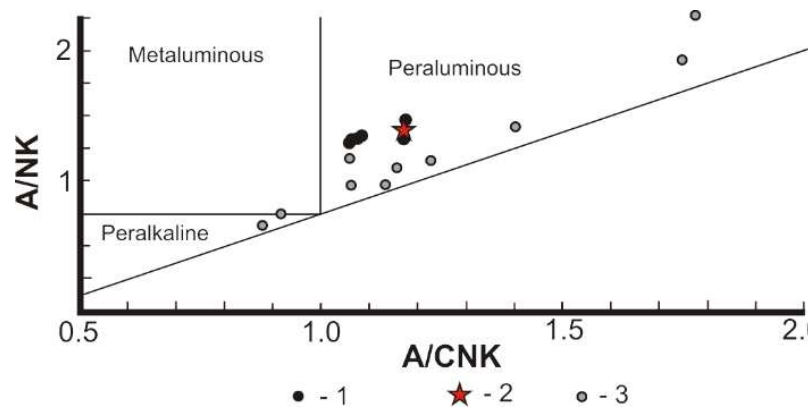

Рис. 2. Составы экспериментального расплава и неоархейских риолитов на диаграмме $\mathrm{A} / \mathrm{CNK}-\mathrm{A} / \mathrm{NK}: 1$ - экспериментальный расплав $\left(950^{\circ} \mathrm{C}, 4\right.$ кбар); 2 - средний состав экспериментального расплава $\left(950^{\circ} \mathrm{C}, 4\right.$ кбар); 3 - неоархейские риолиты.

[Fig. 2. The experimental melt and the Neoarchean rhyolites compositions on the $\mathrm{A} / \mathrm{CNK}-\mathrm{A} / \mathrm{NK}$ diagram: (1) - experimental melt $\left(950^{\circ} \mathrm{C}, 4 \mathrm{kbar}\right) ;(2)$ - average composition of the experimental melt $\left(950^{\circ} \mathrm{C}, 4 \mathrm{kbar}\right) ;(3)$ - Neoarchean rhyolites.]
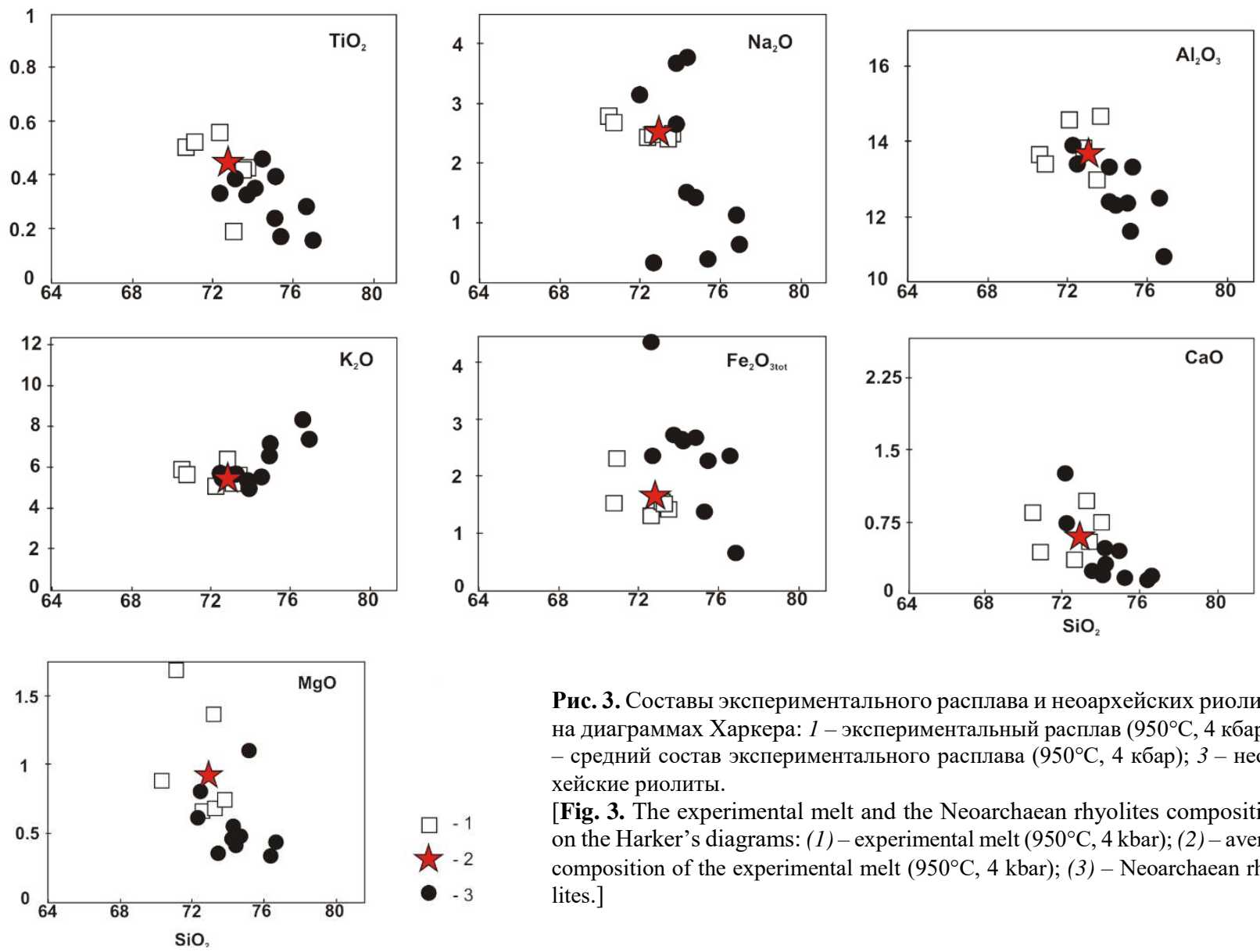

Рис. 3. Составы экспериментального расплава и неоархейских риолитов на диаграммах Харкера: 1 - экспериментальный расплав $\left(950^{\circ} \mathrm{C}, 4\right.$ кбар); 2 - средний состав экспериментального расплава $\left(950^{\circ} \mathrm{C}, 4\right.$ кбар); 3 - неоархейские риолиты.

[Fig. 3. The experimental melt and the Neoarchaean rhyolites compositions on the Harker's diagrams: (1) - experimental melt $\left(950^{\circ} \mathrm{C}, 4 \mathrm{kbar}\right) ;(2)$ - average composition of the experimental melt $\left(950^{\circ} \mathrm{C}, 4 \mathrm{kbar}\right)$; (3) - Neoarchaean rhyo$\begin{array}{ll}\hat{h}-2 & \text { compositi } \\ -3 & \text { lites.] }\end{array}$
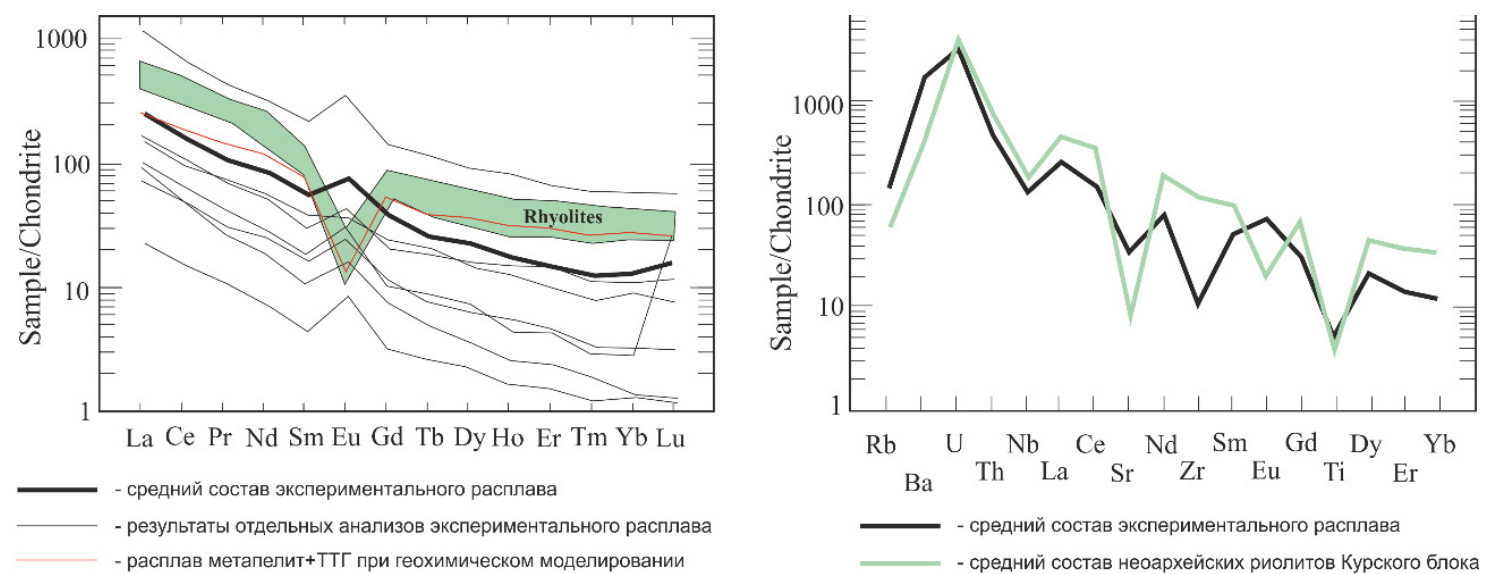

Рис. 4. Диаграммы распределения редких и редкоземельных элементов в экспериментальном расплаве $\left(950{ }^{\circ} \mathrm{C}, 4\right.$ кбар) и неоархейских риолитах.

[Fig. 4. Trace and rare earth elements diagrams for the experimental melt $\left(950^{\circ} \mathrm{C}, 4 \mathrm{kbar}\right)$ and the Neoarchaean rhyolites.] 


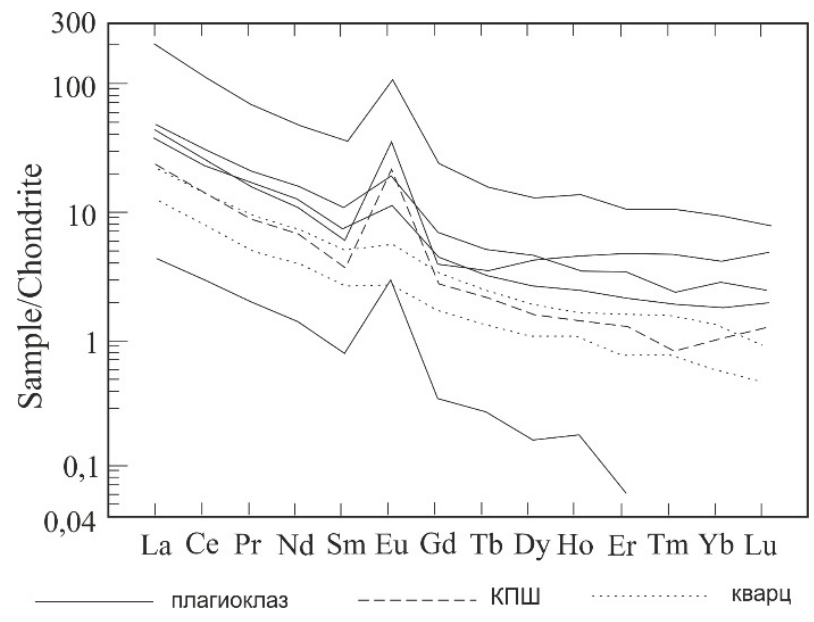

Рис. 5. Диаграммы распределения редкоземельных элементов в плагиоклазе, калиевом полевом шпате и кварце из экспериментального образца $\left(950^{\circ} \mathrm{C}, 4\right.$ кбар).

[Fig. 5. Rare earth elements diagrams for plagioclase, potassium feldspar and quartz from the experimental sample $\left(950^{\circ} \mathrm{C}, 4\right.$ kbar).]

Табл. 2. Содержания петрогенных оксидов и редких элементов в минералах из экспериментального препарата $\left(950^{\circ} \mathrm{C}, 4\right.$ кбар)

[Table 2. Major oxides and trace elements concentrations in minerals from the experimental sample $\left(950^{\circ} \mathrm{C}, 4 \mathrm{kbar}\right)$ ]

\begin{tabular}{|c|c|c|c|c|c|c|c|c|c|c|}
\hline & $\mathrm{Pl}-3$ & Pl-41 & $\mathrm{P} 1-42$ & $\mathrm{Pl}-43$ & $\mathrm{Pl}-44$ & Kfs-50 & Qtz-31 & Qtz-32 & $\mathrm{Bt}$ & Opx \\
\hline 1 & 2 & 3 & 4 & 5 & 6 & 7 & 8 & 9 & 10 & 11 \\
\hline $\mathrm{SiO}_{2}$ & 60.18 & & & & 59.61 & 64.65 & 100.16 & 96.54 & 39.48 & 50.67 \\
\hline $\mathrm{TiO}_{2}$ & 0.08 & & & & - & - & - & - & 2.95 & 0.79 \\
\hline $\mathrm{Al}_{2} \mathrm{O}_{3}$ & 24.29 & & & & 25.55 & 18.85 & 0.03 & 2.02 & 17.03 & 11.39 \\
\hline $\mathrm{FeO}$ & 0.14 & & & & 0.08 & 0.33 & 0.04 & 0.60 & 11.33 & 15.59 \\
\hline $\mathrm{MnO}$ & - & & & & 0.06 & - & 0.08 & 0.08 & - & 0.08 \\
\hline $\mathrm{MgO}$ & 0.11 & & & & 0.07 & 0.07 & - & - & 16.92 & 19.86 \\
\hline $\mathrm{CaO}$ & 5.86 & & & & 7.42 & 0.23 & 0.01 & 0.14 & 0.20 & 0.33 \\
\hline $\mathrm{Na}_{2} \mathrm{O}$ & 6.58 & & & & 6.85 & 2.92 & - & 0.19 & 0.34 & 0.52 \\
\hline $\mathrm{K}_{2} \mathrm{O}$ & 1.02 & & & & 0.54 & 12.28 & - & - & 8.78 & 1.07 \\
\hline$\Sigma$ & 98.26 & & & & 100.28 & 99.34 & 100.31 & 99.57 & 97.03 & 100.32 \\
\hline Ort & 0.06 & & & & 0.03 & 0.73 & & & & \\
\hline $\mathrm{Ab}$ & 0.63 & & & & 0.61 & 0.26 & & & & \\
\hline $\mathrm{An}$ & 0.31 & & & & 0.36 & 0.01 & & & & \\
\hline $\mathrm{Ti}$ & $\begin{array}{c}\text { H.o. } \\
\text { [N/A] }\end{array}$ & $\begin{array}{c}\text { H.o. } \\
\text { [N/A] }\end{array}$ & $\begin{array}{c}\text { H.o. } \\
\text { [N/A] }\end{array}$ & $\begin{array}{c}\text { H.o. } \\
\text { [N/A] }\end{array}$ & $\begin{array}{c}\text { H.o. } \\
\text { [N/A] }\end{array}$ & $\begin{array}{c}\text { H.o. } \\
\text { [N/A] }\end{array}$ & 215 & 550 & & \\
\hline $\mathrm{Li}$ & 36.5 & 72.3 & 16.8 & 14.1 & 2.29 & 7.03 & $\begin{array}{c}\text { H.o. } \\
\text { [N/A] }\end{array}$ & $\begin{array}{c}\text { H.o. } \\
\text { [N/A] }\end{array}$ & & \\
\hline $\mathrm{Sc}$ & 10.6 & 46.6 & 14.5 & 3.84 & 0.41 & 7.51 & 1.27 & 3.51 & & \\
\hline $\mathrm{Cr}$ & 17.6 & 66.6 & 17.3 & 3.52 & 0.31 & 36.0 & 1.32 & 27.3 & & \\
\hline Co & 4.89 & 17.6 & 5.36 & 1.32 & 0.11 & 14.2 & 0.34 & 1.74 & & \\
\hline $\mathrm{Rb}$ & 79.2 & 240 & 70.5 & 63.3 & 5.58 & 38.5 & 18.3 & 32.0 & & \\
\hline $\mathrm{Sr}$ & 985 & 1422 & 92.2 & 74.5 & 72.9 & 137 & 8.1 & 20.3 & & \\
\hline $\mathrm{Y}$ & 5.39 & 13.2 & 3.40 & 4.60 & 0.24 & 1.70 & 1.18 & 2.10 & & \\
\hline $\mathrm{Zr}$ & 4.78 & 35.6 & 3.99 & 15.7 & 0.63 & 2.55 & 1.76 & 2.32 & & \\
\hline $\mathrm{Nb}$ & 7.54 & 35.6 & 6.56 & 4.41 & 0.36 & 3.87 & 1.49 & 2.51 & & \\
\hline Cs & 1.35 & 3.86 & 1.45 & 0.91 & 0.11 & 0.65 & $\begin{array}{c}\text { H.o. } \\
\text { [N/A] }\end{array}$ & $\begin{array}{c}\text { H.o. } \\
\text { [N/A] }\end{array}$ & & \\
\hline $\mathrm{Ba}$ & 1021 & 3833 & 610 & 736 & 89.3 & 1448 & $\begin{array}{c}\text { H.o. } \\
\text { [N/A] }\end{array}$ & $\begin{array}{c}\text { H.o. } \\
\text { [N/A] }\end{array}$ & & \\
\hline $\mathrm{La}$ & 9.86 & 49.0 & 10.1 & 11.7 & 1.03 & 5.74 & 2.95 & 5.09 & & \\
\hline $\mathrm{Ce}$ & 17.2 & 73.8 & 16.1 & 19.0 & 1.79 & 8.98 & 4.88 & 8.89 & & \\
\hline $\operatorname{Pr}$ & 1.52 & 7.17 & 1.66 & 2.00 & 0.19 & 0.85 & 0.49 & 0.91 & & \\
\hline $\mathrm{Nd}$ & 5.26 & 24.4 & 6.30 & 7.67 & 0.64 & 3.18 & 1.87 & 3.38 & & \\
\hline $\mathrm{Sm}$ & 0.95 & 5.92 & 1.11 & 1.62 & 0.12 & 0.58 & 0.40 & 0.79 & & \\
\hline $\mathrm{Eu}$ & 2.01 & 6.20 & 0.67 & 1.01 & 0.17 & 1.11 & 0.16 & 0.33 & & \\
\hline $\mathrm{Gd}$ & 0.84 & 4.99 & 0.92 & 1.42 & 0.07 & 0.57 & 0.36 & 0.69 & & \\
\hline $\mathrm{Tb}$ & 0.13 & 0.61 & 0.13 & 0.19 & 0.01 & 0.08 & 0.05 & 0.09 & & \\
\hline Dy & 1.10 & 3.38 & 0.67 & 1.17 & 0.04 & 0.40 & 0.27 & 0.49 & & \\
\hline Ho & 0.25 & 0.78 & 0.14 & 0.19 & 0.01 & 0.08 & 0.06 & 0.09 & & \\
\hline $\mathrm{Er}$ & 0.78 & 1.79 & 0.36 & 0.56 & 0.01 & 0.21 & 0.13 & 0.26 & & \\
\hline
\end{tabular}


Продолжение Табл. 1

[Continued Table 1]

\begin{tabular}{|c|c|c|c|c|c|c|c|c|c|c|}
\hline 1 & 2 & 3 & 4 & 5 & 6 & 7 & 8 & 9 & 10 & 11 \\
\hline $\mathrm{Tm}$ & 0.12 & 0.28 & 0.05 & 0.06 & 0.00 & 0.02 & 0.02 & 0.04 & & \\
\hline $\mathrm{Yb}$ & 0.68 & 1.66 & 0.31 & 0.47 & 0.01 & 0.17 & 0.10 & 0.22 & & \\
\hline $\mathrm{Lu}$ & 0.12 & 0.21 & 0.05 & 0.06 & 0.00 & 0.03 & 0.012 & 0.024 & & \\
\hline $\mathrm{Hf}$ & 0.11 & 1.22 & 0.10 & 0.51 & 0.02 & 0.09 & $\begin{array}{c}\text { H.o. } \\
{[\text { N/A }]}\end{array}$ & $\begin{array}{c}\text { H.o. } \\
{[\text { N/A }]}\end{array}$ & & \\
\hline $\mathrm{Ta}$ & 0.31 & 1.30 & 0.33 & 0.15 & 0.01 & 0.29 & $\begin{array}{c}\text { H.o. } \\
{[\text { N/A }]}\end{array}$ & $\begin{array}{c}\text { H.o. } \\
{[\text { N/A }]}\end{array}$ & & \\
\hline $\mathrm{Pb}$ & 37.1 & 93.9 & 15.4 & 20.1 & 3.00 & 13.7 & 4.70 & 9.11 & & \\
\hline $\mathrm{Th}$ & 1.62 & 9.47 & 1.59 & 2.24 & 0.24 & 0.98 & 0.66 & 0.72 & & \\
\hline $\mathrm{U}$ & 0.32 & 1.31 & 0.20 & 0.53 & 0.05 & 0.12 & 0.092 & 0.21 & & \\
\hline$\sum \mathrm{REE}$ & 40.8 & 180 & 38.6 & 47.1 & 4.1 & 22.0 & 11.8 & 21.3 & & \\
\hline $\mathrm{Eu} / \mathrm{Eu} *$ & 6.9 & 3.5 & 2.0 & 2.0 & 5.7 & 5.9 & 1.3 & 1.4 & & \\
\hline$(\mathrm{Gd} / \mathrm{Yb})_{\mathrm{N}}$ & 1.0 & 2.49 & 2.46 & 2.50 & 5.79 & 2.77 & 3.0 & 2.6 & & \\
\hline$(\mathrm{La} / \mathrm{Yb})_{\mathrm{N}}$ & 10.4 & 21.2 & 23.4 & 17.8 & 73.9 & 24.2 & 21.2 & 16.8 & & \\
\hline
\end{tabular}

\section{Обсуждение результатов}

Условия образования риолитовых магм Курского блока по геохимическим данным

Результаты геотермометрии, основанные на содержаниях Ті в кварце и цирконе, дают убедительные доказательства высокой (до $1000^{\circ} \mathrm{C}$ ) температуры в источнике генерации кислых магм [2]. Малоглубинные условия магмогенерации, оцененные с привлечением Ti-in-quartz геобарометра [15] в интервале 2.5-2.6 кбар, дополняются данными по геохимии минералов и пород. Геохимические данные по циркону указывают на его конкурентную кристаллизацию одновременно с плагиоклазом, но не с гранатом, что является указанием на давление менее 5 кбар [1]. Геохимические характеристики валовых проб риолитов, такие как высокие отношения $\mathrm{Ga} / \mathrm{Al}$ и высокие концентрации тяжелых РЗЭ с резкой отрицательной Еu аномалией, также являются указанием на ведущую роль плагиоклаза в реститовой ассоциации кислых магм, что является указанием на небольшие глубины. Высокие $\mathrm{Fe} / \mathrm{Mg}$ отношения пород могут служить указанием на преобладание ортопироксена в реститовой ассоциации, что предполагает небольшие давления и относительно сухие условия генерации кислого расплава. Таким образом, все полученные данные указывают на формирование кислых магм при высоких температурах и низких давлениях в условиях верхней коры.

\section{Обзор экспериментов по плавлению} известково-щелочных коровых пород

Рассмотренные выше граничные условия образования риолитовых магм А-типа хорошо согласуются с известными экспериментальными данными по дегидратационному плавлению. Еще в коне XX века высказывались предположения, что граниты А-типа могут быть результатом частичного ( 10-40\%) плавления известково-щелочных кислых магматических пород [16]. Эксперименты по плавлению тоналитового гнейса ( $20 \%$ биотита, $\sim 2 \%$ роговой обманки) показали, что расплавы, полученные при давлении 6-10 кбар, близки к гранитам А-типа, за исключением довольно высокого содержания в них $\mathrm{Al}_{2} \mathrm{O}_{3}(\sim 14$ мас. \%) [17]. Опыты по сухому плавлению синтетического биотитового гнейса в широком диапазоне температур и давлений описаны в работе [6]. Эксперименты при $950^{\circ} \mathrm{C}, 5$ кбар и $925^{\circ} \mathrm{C}, 3$ кбар показали образование расплава с реститом $\mathrm{Qtz}+\mathrm{Pl}+\mathrm{Opx}+\mathrm{Bt}$, очень близкого по составу петрогенных оксидов с полученным в нашем эксперименте $\left(950^{\circ} \mathrm{C}, 4\right.$ кбар). При плавлении высокоглиноземистого тоналита и гранодиорита при давлении 4 кбар и температуре $950^{\circ} \mathrm{C}$ был получен расплав, отвечающий гранитоидам А-типа [7]. В результате был сделан вывод, что дегидратационное плавление известково-щелочных гранитоидов в верхней коре на глубинах менее 15 км является возможным механизмом образования высококремнистых гранитоидов Атипа [7]. Эксперименты по плавлению архейских тоналитов при несколько большем давлении 6-12 кбар не привели к выплавлению калиевых гранитоидов [8]. На этом основании был сделан вывод, что переработка (рециклинг) древней коры, состоящей из ТТГ, не могла стать причиной более молодого калиевого магматизма. Для него необходимо вовлечение в область магмогенерации более фертильных коровых пород и/или сильно обогащенных мантийных расплавов [8].

\section{Сопоставление расчетных и экспериментальных ре-} зультатов для неоархейских риолитов Курского блока

Для оценки применимости рассматриваемой модели выплавления кислых магм было проведено моделирование содержаний РЗЭ. На основании вариаций Lu-Hf модельных возрастов циркона из риолитов можно предположить, что последние были образованы за счет плавления метапелитов и ТТГ, поэтому в качестве источника при моделировании была выбрана смесь, состоящая из 50 мас. \% метапелита и 50 мас. \% ТТГ. Степень плавления (20\%) и состав рестита $(50 \mathrm{Pl}+35 \mathrm{Opx}+10 \mathrm{Bt}+5 \mathrm{Ilm})$ были приняты в соответствии с экспериментальными данными по плавлению тоналита при давлении 4 кбар [7]. 
Таким образом, кислые расплавы, материнские для изученных риолитов и гранитов с возрастом 2.61 млрд лет, могли образоваться при 20\% дегидратационном плавлении смеси метапелит-ТТГ в равновесии с IlmBt-Opx-Pl реститом при давлении не более 4 кбар. Граниты атаманского комплекса кристаллизовались на более глубоких уровнях и содержали в себе примесь Орх$\mathrm{Pl}$ реститовой или кумулусной компоненты, что определило их геохимические отличия от риолитов, освобожденных от этих фаз в ходе перемещения расплавов на более высокие уровни коры.

Экспериментальный расплав, полученный при $950^{\circ} \mathrm{C}$ и 4 кбар, обнаруживает умеренные вариации низких содержаний редких и рассеянных элементов, за исключением одной точки, где концентрации очень высокие (табл. 1). Хорошо известно, что несовместимые высокозарядные и редкоземельные (за исключением Eu) элементы в гранитоидах концентрируются в акцессорных минералах $[18,19,20]$. Именно от их присутствия зависит «бюджет» редкоземельных и высокозарядных элементов в кислых магмах. При определении содержаний редких и редкоземельных элементов в неоархейских риолитах Курского блока для анализа отбирались образцы керна, которые были раздроблены и растерты в пудру. Из полученных проб методом квартования отбиралась усредненная навеска. При пробоподготовке содержание акцессорных минералов (и соответственно редких и редкоземельных элементов) усредняется и примерно соответствует таковому в исходной породе. Специфика анализа LA-ICP-MS для экспериментального расплава такова, что анализ проводился на участке диаметром 30-40 мкм. Если в этой области отсутствуют микровключения акцессорных фаз, то при анализе мы получаем искаженный состав стекла (экспериментального расплава), обедненный редкими и рассеянными элементами (табл. 2). Если же в области лазерной абляции оказались микровключения акцессорных минералов, то искажения обусловлены их аномально высокими содержаниями, как, например, в точке L-16. Исходя из этого, нами в качестве состава экспериментального расплава, приближенного к истинному, был принят средний состав из 7 определений содержаний редких и редкоземельных элементов в разных точках (рис. 4). На спайдер-диаграммах кривые распределения редких и редкоземельных элементов в расчётном и экспериментальном расплавах и в неоархейских риолитах близки, за исключением содержаний европия, для которого характерны положительные и отрицательные аномалии соответственно. Основным концентратором Еu являются полевые шпаты (рис. 5). Отрицательные аномалии в риолитах объясняются фракционированием плагиоклаза и удалением его из расплава. В эксперименте такое фракционирование невозможно, поэтому стекло, как и реститовый плагиоклаз, демонстрируют положительные аномалии $\mathrm{Eu}$ (рис. 4).

Реститовая ассоциация Qtz+Pl+Kfs+Bt+Sil+Opx в эксперименте отличается от рассчитанной Ilm-Bt-Opx-
Pl. Появление в рестите силлиманита и калиевого полевого шпата, по-видимому, связано с присутствием в стартовом материале значительного количества (50\%) глиноземистого метапелита.

Температура, рассчитанная по TiQ термометру [21] при давлении 4 кбар в среднем близка к $950^{\circ} \mathrm{C}$, что свидетельствует о корректности экспериментов.

\section{Выводы}

Проведены эксперименты по дегидрационному плавлению смеси природных трондьемита и метапелита из образцов архейских пород при давлениях 4 кбар и температурах $850^{\circ} \mathrm{C}$ и $950^{\circ} \mathrm{C}$. При температуре $850^{\circ} \mathrm{C}$ мы получили метапелитовый гранулит с минеральной ассоциацией $\mathrm{Qtz}+\mathrm{Pl}+\mathrm{Kfs}+\mathrm{Bt}+\mathrm{Crd}+\mathrm{Sil}$ без признаков плавления. Наиболее интересные результаты для решения поставленной задачи мы получили при температуре $950^{\circ} \mathrm{C}$. Фракция расплава составила около $20 \%$ с реститом состава $\mathrm{Qtz}+\mathrm{Pl}+\mathrm{Kfs}+\mathrm{Bt}+\mathrm{Sil}+\mathrm{Opx}$. По содержанию петрогенных оксидов состав экспериментального расплава близок к неоархейскому риолиту Атипа из Курского блока. Более сложным оказалось интерпретировать распределение редких и редкоземельных элементов в экспериментальном препарате из-за локальности метода LA-ICP-MS. На концентрации данных элементов сильно влияет наличие или отсутствие микровключений акцессорных минералов, поэтому нам пришлось ориентироваться на усредненный состав, определенный в семи точках. В итоге кривые распределения редких и редкоземельных элементов на спайдер-диаграммах в экспериментальном и расчетном расплаве близки к неоархейским калиевым риолитам. Исключение составляют резкие положительные аномалии европия в экспериментальном стекле. Неоархейские риолиты, наоборот, демонстрируют отрицательные аномалии $\mathrm{Eu}$, которые объясняются эффективным фракционированием плагиоклаза и удалением его из расплава. В эксперименте такое фракционирование невозможно.

Таким образом, наши экспериментальные исследования показали возможность образования неоархейских риолитовых магм А-типа при высоких температурах на небольших глубинах в результате частичного (около 20\%) плавления палеоархейской коры, состоящей из ТТГ и метаосадков в Курском блоке Сарматии.

Конфликт интересов. Авторы декларируют отсутствие явных и потенциальных конфликтов интересов, связанных с публикацией настоящей статьи.

\section{ЛИТЕРАТУРА}

1. Savko K. A., Samsonov A. V., Kholina N. V., Larionov A. N., Zaitseva M. V., Korish E. H., Bazikov N. S., Terentiev R. A. 2.6 Ga high-Si rhyolites and granites in the Kursk Domain, Eastern Sarmatia: Petrology and application for the Archaean palaeocontinental correlations // Precambrian Res. 2019. Vol. 322. P. 170192. DOI: $10.1016 /$ j.precamres.2019.01.006

2. Холина Н. В., Савко К. А., Холин В. М. Высокие температуры кристаллизации неоархейских риолитов Курского блока Воронежского кристаллического массива: результаты 
минеральной термометрии // Вестник Воронежского государственного университета. Серия: Геология. 2016. № 3. С. 53-60.

3. Gao P., Yong-Fei Zheng Y.-F., Zi-Fu Zhao Z.-F. Experimental melts from crustal rocks: A lithochemical constraint on granite petrogenesis // Lithos. 2016. Vol. 266-267. P. 133-157. DOI: 10.1016/j.lithos.2016.10.005

4. Frost C.D., Frost B.R. On ferroan (A-type) granitoids: their compositional variability and modes of origin // Journal of Petrology. 2011. Vol. 52. No. 3. P. 9-53. DOI: 10.1093/petrology/egq070

5. Савко К. А., Холина Н. В., Самсонов А. В., Кориш Е. Х., Червяковская М. В., Базиков Н. С., Ларионов А. Н. Петротип неоархейского атаманского комплекса гранитов Курского блока Сарматии: геохимия, геохронология, изотопная систематика // Вестник Воронежского государственного университета. Серия: Геология. 2020. № 2. С. 20-43. DOI: 10.17308/geology.2020.2/2857

6. Patiño-Douce A. E., Beard J. S. Dehydration-melting of biotite gneiss and quartz amphibolites from 3 to $15 \mathrm{kbar} / / \mathrm{J}$. Petrology. 1995. Vol. 36. P. 707-738. DOI: 10.1093/petrology/36.3.707

7. Patiño-Douce A. E. Generation of metaluminous A-type granites by low-pressure melting of calc-alkaline granitoids // Geology. 1997. Vol. 25. P. 43-746. DOI: 10.1130/00917613(1997)025<0743:GOMATG $>2.3 . C O ; 2$

8. Watkins J. M., Clemens J. D., Treloar P. J. Archaean TTGs as sources of younger granitic magmas: melting of sodic metatonalites at 0.6-1.2 Gpa // Contrib. Mineral. Petrol. 2007. Vol. 154. P. 91-110. DOI: 10.1007/s00410-007-0181-0

9. Schindlbeck J. C., Kutterolf S., Freundt A., Alvarado G. E., Wang K. L., Straub S. M., Hemming S. R., Frische M., Woodhead J. D. Late Cenozoic tephrostratigraphy offshore the southern Central American Volcanic Arc: 1. Tephra ages and provenance // Geochemistry, Geophys. Geosystems. 2016. Vol. 17. P. 46414668. DOI: $10.1002 / 2016 \mathrm{GC} 006503$

10. Norman M. D., Pearson N. J., Sharma A., Griffin W.L. Quantitative analysis of trace elements in geological materials by laser ablation ICPMS: instrumental operating conditions and calibration values of NIST glasses // Geostandards Newsletter. 1996. Vol. 20. P. 247-261. DOI: 10.1111/j.1751-908X.1996.tb00186.x 11. Van Achterberg E., Ryan C. G., Jackson S. E., Griffin W. Data reduction software for LA-ICP-MS: appendix // Laser ab-
lation-ICP-Mass Spectrometry in the Earth Sciences: Principles and Applications. Ed: P.J. Sylvester. Ottawa, Mineralogical Association of Canada, 2001. P. 239-243.

12. Whitney D. L., Evans B. W. Abbreviations for names of rockforming minerals // Amer. Mineral. 2010. Vol. 95. P. 185-187. DOI: $10.2138 / \mathrm{am} .2010 .3371$

13. Савко К. А. Реакционные структуры и эволюция метаморфизма шпинелевых гранулитов Воронежского кристаллического массива // Петрология. 2000. № 2. С. 165-181.

14. Savko K. A., Samsonov A. V., Larionov A. N., Chervyakovskaya M. V., Korish E. H., Larionova Yu. O., Bazikov N. S., Tsybulyaev S. V. A buried Paleoarchean core of the Eastern Sarmatia, Kursk block: U-Pb, Lu-Hf and Sm-Nd isotope mapping and paleotectonic application // Precambrian Res. 2021. Vol. 353. 106021. DOI: 10.1016/j.precamres.2020.106021

15. Huang R., Audetat A. The titanium-in-quartz (TitaniQ) thermo-barometer: a critical examination and recalibration // Geochim. Cosmochim. Acta. 2012. Vol. 84. P. 75-89. DOI: 10.1016/j.gca.2012.01.009

16. Anderson J. L. Proterozoic anorogenic granite plutonism of North America // Proterozoic geology: Selected papers from an international Proterozoic symposium. Eds: L.G. Medaris et al. Geological Society of America Memoir 161. 1983. P. 133-154. DOI: 10.1130/MEM161-p133

17. Skjerlie K. P., Johnston A. D. Fluid-absent melting behavior of an F-rich tonalitic gneiss at mid-crustal pressures: Implications for the generation of anorogenic granites // Journal of Petrology. 1993. Vol. 34. pp. 785-815. DOI: $10.1093 /$ petrology/34.4.785

18. Bea F. Controls on the trace element composition of crustal melts // Transactions of the Royal Society of Edinburgh, Earth Sci. 1996. Vol. 87. P. 33-42. DOI: 10.1017/S0263593300006453 19. Villaros A., Stevens G., Moyen J.-F., Buick I.S. The trace element compositions of S-type granites: evidence for disequilibrium melting and accessory phase entrainment in the source // Contrib. Mineral. Petrol. 2009. Vol. 158. P. 543-561. DOI: 10.1007/S00410-009-0396-3

20. Clemens J. D., Stevens G. What controls chemical variation in granitic magmas? // Lithos. 2012. vol. 134-135. P. 317-329. DOI: 10.1016/j.lithos.2012.01.001

21. Wark D. A., Watson E. B. TitaniQ: a titanium-in-quartz geothermometer // Contrib. Mineral. Petrol. 2006. Vol. 152. P. 743754. DOI: 10.1007/s00410-006-0132-1 


\title{
PETROLOGY, VOLCANOLOGY, GEOCHEMISTRY
}

UDC 552:11

ISSN 1609-0691

DOI: https://doi.org/10.17308/geology.2021.2/3486

Received: 28.04 .2021

Accepted: 20.05 .2021

Published online: 30.06 .2021

\section{Palaeoarchaean TTGs and metapelites as protoliths of the Neoarchaean A-type rhyolites from the Kursk block, Sarmatia: the dehydrating melting experimental results}

\author{
(C) 2021 K. A. Savko ${ }^{1,2 \varpi}$, A. V. Samsonov ${ }^{3}$, M. A. Golunova ${ }^{4}$, \\ K.-L. Wang ${ }^{5}$, N. S. Bazikov ${ }^{1}$, N. V. Kholina ${ }^{1}$, T. N. Polyakova ${ }^{1}$ \\ ${ }^{1}$ Voronezh State University, 1 Universitetskaya pl., Voronezh 394018, Russian Federation \\ ${ }^{2}$ Russian State University for Geological Prospecting, Stary Oskol Branch, Lenina st., \\ 14/13, Stary Oskol 309514, Belgorodskaya oblast, Russian Federation \\ ${ }^{3}$ Institute of Geology of Ore Deposits, Petrography, Mineralogy and Geochemistry of the Russian \\ Academy of Sciences (IGEM RAS), 35 Staromonetny per., Moscow 119017, Russian Federation \\ ${ }^{4}$ Institute of Experimental Mineralogy, Russian Academy of Sciences, \\ Academica Osypyana, 4, Chernogolovka 142432, Moscow region, Russian Federation \\ ${ }^{5}$ Institute of Earth Sciences, Academia Sinica, 128 Academia Road Sec. 2, \\ Nankang Taipei 115, Taiwan R.O.C.
}

\begin{abstract}
Introduction: The 2.61 Ga intraplate A-type magmatism in the Kursk block of the Eastern Sarmatia is represented by volcano-plutonic association of potassium high-silica rhyolites and granites. Isotopic data suggests that the crustal source of these rocks was heterogeneous. According to the modeling data parental melts could have been formed due to metapelite+TTG mixture $20 \%$ dehydrating melting at pressure no more than 4 kbar.

Methodology: The experimental melting of possible protoliths was carried out to verify the results of geochemical data modeling. The composition of melt and restite minerals was analyzed in the experimental samples.

Results and discussion: The concentrations of major oxides are close in the experimental melt obtained at $950^{\circ} \mathrm{C}$, and in the Neoarchaean rhyolites. Average rare earth elements distribution in the experimental melt is also close to the Neoarchaean rhyolites.

Conclusion: The experimental study indicated that the Neoarchaean rhyolite A-type magmas could have been formed at high temperatures and shallow depths as a result of partial melting of the Palaeoarchaean crust consisting of TTGs and metasediements in the Kursk block of Sarmatia.

Keywords: Archaean, rhyolite, protolith, experimental melting.
\end{abstract}

Funding: This work was supported by the RFBR project No. 19-05-00159.

For citation: Savko K. A., Samsonov A. V., Golunova M. A., Wang K.-L., Bazikov N. S., Kholina N. V., Polyakova T. N. Vestnik Voronezhskogo gosudarstvennogo universiteta. Seriya: Geologiya - Proceedings of Voronezh State University. Series: Geology, 2021, no. 2, pp. 29-40. DOI: https://doi.org/10.17308/geology.2021.2/3486

\footnotetext{
${ }^{凶}$ Konstantin A. Savko, e-mail: ksavko@geol.vsu.ru
} 
Conflict of interests: The authors declare the absence of obvious and potential conflicts of interest related to the publication of this article.

\section{REFERENCES}

1. Savko K. A., Samsonov A. V., Kholina N. V., Larionov A. N., Zaitseva M. V., Korish E. H., Bazikov N. S., Terentiev R. A. 2.6 Ga high-Si rhyolites and granites in the Kursk Domain, Eastern Sarmatia: Petrology and application for the Archaean palaeocontinental correlations. Precambrian Res, 2019, vol. 322, pp. 170192. DOI: 10.1016/j.precamres.2019.01.006

2. Kholina N. V., Savko K. A., Kholin V. M. High temperature crystallization Neoarchean rhyolites of the Kursk block, Voronezh Crystalline Massif: The mineral thermometry results. Vestnik Voronezhskogo gosudarstvennogo universiteta. Seriya: Geologiya - Proceedings of Voronezh State University. Series: Geology, 2016, no. 3, pp. 53-60. (in Russ.).

3. Gao P., Yong-Fei Zheng Y.-F., Zi-Fu Zhao Z.-F. Experimental melts from crustal rocks: A lithochemical constraint on granite petrogenesis. Lithos, 2016, vol. 266-267, pp. 133-157. DOI: 10.1016/j.lithos.2016.10.005

4. Frost C. D., Frost B. R. On ferroan (A-type) granitoids: their compositional variability and modes of origin. Journal of Petrology, 2011, vol. 52, no. 3, pp. 9-53. DOI: 10.1093/petrology/egq070

5. Savko K. A., Kholina N. V., Samsonov A. V., Korish E. Kh., Chervyakovskaya M. V., Bazikov N. S., Larionov A. N. The petrotype of the Neoarchaean Atamansky granite complex (Kursk block, Sarmatia): geochemistry, geochronology, and isotopic taxonomy. Vestnik Voronezhskogo gosudarstvennogo universiteta. Seriya: Geologiya - Proceedings of Voronezh State University. Series: Geology, 2020, no. 2, pp. 20-43. DOI: 10.17308/geology.2020.2/2857 (in Russ.).

6. Patiño-Douce A. E., Beard J. S. Dehydration-melting of biotite gneiss and quartz amphibolites from 3 to 15 kbar. J. Petrology, 1995, vol. 36, pp. 707-738. DOI: 10.1093/petrology/36.3.707

7. Patiño-Douce A. E. Generation of metaluminous A-type granites by low-pressure melting of calc-alkaline granitoids. Geology, 1997, vol. 25, pp. 43-746. DOI: 10.1130/00917613(1997)025<0743:GOMATG $>2.3 . C O ; 2$

8. Watkins J. M., Clemens J. D., Treloar P. J. Archaean TTGs as sources of younger granitic magmas: melting of sodic metatonalites at 0.6-1.2 Gpa. Contrib. Mineral. Petrol, 2007, vol. 154, pp. 91-110. DOI: $10.1007 / \mathrm{s} 00410-007-0181-0$

9. Schindlbeck J. C., Kutterolf S., Freundt A., Alvarado G. E., Wang K. L., Straub S. M., Hemming S. R., Frische M., Woodhead J. D. Late Cenozoic tephrostratigraphy offshore the southern Central American Volcanic Arc: 1. Tephra ages and provenance. Geochemistry, Geophys. Geosystems, 2016, vol. 17, pp. 46414668. DOI: 10.1002/2016GC006503
10. Norman M. D., Pearson N. J., Sharma A., Griffin W. L. Quantitative analysis of trace elements in geological materials by laser ablation ICPMS: instrumental operating conditions and calibration values of NIST glasses. Geostandards Newsletter, 1996, vol. 20, pp. 247-261. DOI: 10.1111/j.1751-908X.1996.tb00186.x 11. Van Achterberg E., Ryan C. G., Jackson S. E., Griffin W. Data reduction software for LA-ICP-MS: appendix. Laser ablation-ICP-Mass Spectrometry in the Earth Sciences: Principles and Applications. Ed: P.J. Sylvester. Ottawa, Mineralogical Association of Canada, 2001, pp. 239-243.

12. Whitney D. L., Evans B. W. Abbreviations for names of rockforming minerals. Amer. Mineral, 2010, vol. 95, pp. 185-187. DOI: $10.2138 / \mathrm{am} .2010 .3371$

13. Savko K. A. Reaction Textures and Metamorphic Evolution of Spinel Granulites in the Voronezh Crystalline Massif. Petrology, 2000, vol. 8, no. 2, pp. 165-181. (in Russ.).

14. Savko K. A., Samsonov A. V., Larionov A. N., Chervyakovskaya M. V., Korish E. H., Larionova Yu. O., Bazikov N. S., Tsybulyaev S. V. A buried Paleoarchean core of the Eastern Sarmatia, Kursk block: U-Pb, Lu-Hf and Sm-Nd isotope mapping and paleotectonic application. Precambrian Res., 2021, vol. 353, 106021. DOI: 10.1016/j.precamres.2020.106021

15. Huang R., Audetat A. The titanium-in-quartz (TitaniQ) thermo-barometer: a critical examination and recalibration. Geochim. Cosmochim. Acta, 2012, vol. 84, pp. 75-89. DOI: 10.1016/j.gca.2012.01.009

16. Anderson J. L. Proterozoic anorogenic granite plutonism of North America. Proterozoic geology: Selected papers from an international Proterozoic symposium. Eds: L.G. Medaris et al. Geological Society of America Memoir 161. 1983, pp. 133-154. DOI: 10.1130/MEM161-p133

17. Skjerlie K. P., Johnston A. D. Fluid-absent melting behavior of an F-rich tonalitic gneiss at mid-crustal pressures: Implications for the generation of anorogenic granites. Journal of Petrology, 1993 , vol. 34, pp. 785-815. DOI: 10.1093/petrology/34.4.785

18. Bea F. Controls on the trace element composition of crustal melts. Transactions of the Royal Society of Edinburgh, Earth Sci., 1996, vol. 87, pp. 33-42. DOI: 10.1017/S0263593300006453

19. Villaros A., Stevens G., Moyen J.-F., Buick I. S. The trace element compositions of S-type granites: evidence for disequilibrium melting and accessory phase entrainment in the source. Contrib. Mineral. Petrol., 2009, vol. 158, pp. 543-561. DOI: 10.1007/S00410-009-0396-3

20. Clemens J. D., Stevens G. What controls chemical variation in granitic magmas? Lithos, 2012, vol. 134-135, pp. 317-329. DOI: $10.1016 /$ j.lithos.2012.01.001

21. Wark D. A., Watson E. B. TitaniQ: a titanium-in-quartz geothermometer. Contrib. Mineral. Petrol., 2006, vol. 152. pp. $743-$ 754. DOI: 10.1007/s00410-006-0132-1
Савко Константин Аркадьевич - д.г.-м.н., профессор, заведующий кафедрой полезных ископаемых и недропользования, Воронежский государственный университет, Воронеж, Российская Федерация; E-mail: ksavko@geol.vsu.ru; ORCID http://orcid.org/0000-0002-7291-7024

Самсонов Александр Владимирович - д.г.-м.н., главный научный сотрудник, Институт геологии рудных месторождений, петрографии, минералогии и геохимии РАН, Москва, Российская Федерация; E-mail: samsonov@igem.ru; ORCID http://orcid.org/0000-0003-4101-6159
Konstantin A. Savko - Dr. habil. in Geol.-Min., Professor, Head of the Department of Mineral Resources and Mineral Management Studies, Voronezh State University, Voronezh, Russian Federation; E-mail: ksavko@geol.vsu.ru; ORCID http://orcid.org/0000-0002-7291-7024

Alexander V. Samsonov - Dr. habil. in Geol.-Min., Associate Member of the RAS, chief researcher, Institute of Ore Deposits, Petrography, Mineralogy and Geochemistry RAS, Moscow, Russian Federation; E-mail: samsonov@igem.ru; ORCID http://orcid.org/0000-0003-4101-6159 
Голунова Мария Алексеевна - к.г.-м.н., старший научный сотрудник, Институт экспериментальной минералогии РАН,

Черноголовка, Московская область, Российская Федерация; E-mail: nov@iem.ac.ru;

ORCID http://orcid.org/0000-0002-7251-1876

Вонг Куо-Лунг - PhD, профессор, Институт наук о Земле

Академии Синика, Тайбей, Тайвань;

E-mail: kwang@earth.sinica.edu.tw;

ORCID http://orcid.org/0000-0002-6447-2168

Базиков Николай Сергеевич - к.г.-м.н., доцент кафедры полезных ископаемых и недропользования, Воронежский государственный университет, Воронеж, Российская Федерация; E-mail: nickolasss@yandex.ru; ORCID http://orcid.org/0000-0002-0847-6498

Холина Наталья Викторовна - к.г.-м.н., преподаватель кафедры полезных ископаемых и недропользования, Воронежский государственный университет, Воронеж, Российская Федерация; E-mail: holina_geol@mail.ru; ORCID http://orcid.org/0000-0002-7220-4358

Полякова Татьяна Николаевна - к.г.-м.н., доцент кафедры полезных ископаемых и недропользования, Воронежский государственный университет, Воронеж, Российская Федерация; E-mail: imgre2010@yandex.ru;

ORCID http://orcid.org/0000-0002-9957-9002

Авторы прочитали и одобрили окончательный вариант рукописи
Mariya A. Golunova - PhD in Geol.-Min., senior research fellow, Institute of Experimental Mineralogy, RAS, Chernogolovka, Moscow region, Russian Federation;

E-mail: nov@iem.ac.ru;

ORCID http://orcid.org/0000-0002-7251-1876

Wang Kuo-Lung - PhD in Geology, professor, Institute of Earth Sciences, Academia Sinica, Taipei, Taiwan;

E-mail: kwang@earth.sinica.edu.tw;

ORCID http://orcid.org/0000-0002-6447-2168

Nikolay S. Bazikov - PhD in Geol.-Min., associate professor, Department of Mineral Resources and Mineral Management Studies, Voronezh State University, Voronezh, Russian Federation; E-mail: nickolasss@yandex.ru; ORCID http://orcid.org/0000-0002-0847-6498

Natalya V. Kholina - PhD in Geol.-Min., lecturer, Department of Mineral Resources and Mineral Management Studies, Voronezh State University, Voronezh, Russian Federation;

E-mail: holina_geol@mail.ru; ORCID http://orcid.org/0000-0002-7220-4358

Tatiana N. Polyakova - PhD in Geol.-Min., associate professor, Department of Mineral Resources and Mineral Management Studies, Voronezh State University, Voronezh, Russian Federation; E-mail: imgre2010@yandex.ru;

ORCID http://orcid.org/0000-0002-9957-9002

All authors have read and approved the final manuscript 